\title{
Do residents of food deserts express different food buying preferences compared to residents of food oases? A mixed-methods analysis
}

\author{
Renee E Walker ${ }^{1,2^{*}}$, Jason Block ${ }^{3}$ and Ichiro Kawachi ${ }^{4}$
}

\begin{abstract}
Background: Many people lack access to food stores that provide healthful food. Neighborhoods with poor supermarket access have been characterized as "food deserts" (as contrast with "food oases"). This study explored factors influencing food buying practices among residents of food deserts versus food oases in the city of Boston, USA.

Methods: We used the mixed-methods approach of concept mapping, which allows participants to identify, list, and organize their perceptions according to importance. Resulting maps visually illustrate priority areas.

Results: Sixty-seven low-income adults completed the concept mapping process that identified 163 unique statements (e.g. relating to affordability, taste, and convenience) that influence food buying practices. Multivariate statistical techniques grouped the 163 statements into 8 clusters or concepts. Results showed that average cluster ratings and rankings were similar between residents of food deserts and food oases.

Conclusions: The implication of this study pertains to the importance of community resources and emergency food assistance programs that have served to minimize the burden associated with hunger and poor food access among low-income, urban populations.
\end{abstract}

Keywords: Food access, Food desert, Food oasis, Food buying practices, Concept mapping, Low-income

\section{Background}

Neighborhood differences in the local food environment have been increasingly implicated in the rising prevalence of obesity in the United States. Studies have reported an association between neighborhood food environment and obesity prevalence in the United States. Maddock [1] found a positive association between fast food restaurant density and obesity prevalence. A study by Inagami and colleagues [2] showed a higher body mass index (BMI) among those who shopped in disadvantaged neighborhoods - defined by lower sociocenomic status. Additionally, two studies by Morland et al., $[3,4]$ showed that obesity prevalence was lower in areas where supermarkets were located compared to areas

\footnotetext{
* Correspondence: walker36@uwm.edu.

'Department of Society, Human Development and Health, Harvard School of Public Health, 401 Park Drive, Room 445-C, Boston, MA 02215, USA

${ }^{2}$ University of Wisconsin-Milwaukee, Joseph J. Zilber School of Public Health,

Alumni House 327, P.O. Box 413, Milwaukee, WI 53201-0413, USA

Full list of author information is available at the end of the article
}

with grocery stores or fast food restaurants. The presence of a supermarket is often viewed as the "gold standard" in food access given the lower costs, increased quantity and improved quality of food items available at chain supermarkets compared to their non-chain counterparts. Despite support for the association between supermarket access and obesity prevalence, there are neighborhoods at increased risk for diet-related health outcomes due to the absence of a supermarket. Particular attention has been paid to neighborhoods that lack a supermarket - termed "food deserts" - given the convenience that shopping locally affords residents [5]. These areas devoid of supermarkets have been described by Walker et al. [6] in a comprehensive literature review of food deserts in the United States. The review identified four thematic areas of ongoing research, including: (a) local availability of supermarkets; (b) racial/ethnic disparities in food access; (c) socioeconomic disparities in food access; and (d) differences in chain versus nonchain stores [6]. Disparities in the neighborhood food 
environment have prompted research exploring the impact of the local food environment on food purchasing behavior. Studies exploring the intersection between the neighborhood food environment and food purchasing behavior have showed that living in a disadvantaged neighborhood is associated with greater consumption of energy-dense foods $[7,8]$. Research by Cummins and Macintyre [9] suggests that the neighborhood food environment has an independent effect on diet by influencing food buying practices. Similar findings were observed in studies that showed a positive association between proximity to a supermarket and individual diet $[10,11]$ and studies that found a positive association between the presence of a neighborhood supermarket and increased consumption of fruits and vegetables [12-14]. On the other hand, fewer nutrient-dense food options available at neighborhood food stores has been associated with lower consumption of these foods by local residents [15]. However, one of the challenges in this field of research is the extent to which causality can be attributed to local variations in the food environment [16]. That is, even if variations in the quality of the local food environment can be mapped on to local variations in nutritional quality and obesity prevalence, it does not necessarily prove that one caused the other. A correlation between local food environments and obesity rates could simply reflect the food preferences of residents. Alternatively, confounding by unmeasured variables may be explaining the correlations observed between food environments and obesity rates. Thus, from a supply-side perspective, grocery owners are unlikely to stock fresh produce on their shelves in neighborhoods where residents are unlikely to demand them. However, it is important to note that interactions between the neighborhood food environment, diet quality and subsequent health outcomes is multifocal in nature whereby causation involves not one pathway, but multiple pathways.

Few studies have directly examined the food preferences of residents in disadvantaged areas. Eikenberry and Smith conducted a study to identify motivators, barriers and promoters of healthy eating among select rural and urban food deserts in Minnesota [17]. Study participants expressed a lack of desire to consume fresh produce even when they were made available [18]. Similarly, Walker and colleagues found that low-income residents of a food desert did not prefer to consume fruits and vegetables due to their aftertaste [19]. While these findings are not generalizable to residents of other food deserts, it begs further exploration of the influence of food preference.

Food preferences have been described in the literature as influencing food buying and consumption practices. Locher et al., [20] explored how psychosocial factors (motivation, perceived barriers, social demographics, and dietary quality) influence food choices among homebound older adults. Findings from this study suggested that sensory factors, specifically taste and aesthetics, were primary motivators involved in food choice $[20,21]$. Other studies have explored how cultural attitudes [22] and perceptions of healthy eating and the food environment influence food choice $[23,24]$. These studies indicated that taste, texture, and appearance were more important for food choices than nutritional content [22]. This evidence supports the argument that food preference is a strong predictor of food consumption and can serve to promote (or deter) healthy eating.

In addition to food preferences being strong predictors in food buying and consumption practices, consumers often express a preference for type of store patronized. Many paramount studies exploring consumer food shopping behavior have identified factors including location, variety of goods, store loyalty and store policies as reasons why a particular store was patronized over another [25-27]. In the case of neighborhood convenience and corner stores, it is believed that clerk personality and established friendships between store owners and patrons foster store loyalty [25]. This is especially salient in neighborhoods where chain supermarkets are not located. The implication is that residents of these neighborhoods without a supermarket may view the role of the independent store as an anchor within the community thereby encouraging patronage. Subsequently, the food items available within these stores are important for considering food purchasing and consumption behaviors.

Given the influence the neighborhood food environment has on food buying practices among local residents, we sought to explore factors influencing food buying practices among low-income residents with differential supermarket access in the present study. We conducted a mixed-method approach based on concept mapping $[28,29]$ to ascertain the food purchasing practices and preferences of two contrasting neighborhoods in the city of Boston, MA. We hypothesized that differences in food buying practices and food preferences would be identified based on residing in a neighborhood categorized a food desert compared to a food oasis.

\section{Methods}

The geographic unit of analysis for this study was the zip code, which served as our model of a neighborhood. Zip codes in the United States do not represent a geographical area, per se, but are a network of roads and addresses used for the purpose of mail delivery [30,31]. Therefore, there is great variability in the size of a zip code. For example, Grubesic [30] reported an average zip code size in the state of Wyoming to be 1,430 square kilometers $\left(\mathrm{km}^{2}\right)$ compared to $12.8 \mathrm{~km}^{2}$ for an average zip code size in the state of New Jersey. Despite this 
variability, zip codes are frequently used as the unit of analysis in research given their geographical context [30]. We selected four zip codes for the study - two characterized as food deserts and two as food oases. The average land area for the food deserts was $8.0 \mathrm{~km}^{2}(3.1$ square miles) compared to $3.6 \mathrm{~km}^{2}$ (1.4 square miles) for the food oases [32]. We defined a food desert as a zip code that does not have a chain supermarket within 0.5 miles of the center of the zip code. Conversely, we defined a food oasis as a zip code that does have a chain supermarket within 0.5 miles of the center of the zip code. The definition of the buffer zone is consistent with the literature, with 0.5 miles commonly perceived as a reasonable walking distance for an adult to carry home bags of groceries [33]. To identify Boston zip codes selected for the study, two approaches were used. First, we examined the online yellow pages (www.yellowpages. com) to identify zip codes that do not have supermarket access. This is consistent with other studies that utilized yellow pages to identify resources in proximity to a specific unit of area $[34,35]$. Second, we examined U.S. census data to characterize each zip code based on median household income. The selected zip codes had some of the lowest median household incomes for the city of Boston. We matched the selected food deserts with comparable food oases on various demographic characteristics including median household income, age, race/ ethnicity, and educational attainment.

\section{Recruitment}

We placed advertisements in popular print and online newspapers. Print advertisements ran on three nonconsecutive days over a period of 3 weeks. Online advertisements appeared continuously for a period of three weeks. The advertisement included the zip codes of interest and a phone number that potential participants were asked to call for additional information. Participants were expected to meet three inclusion criteria: 1. At least 18 years of age; 2. A current resident of one of the study zip codes; and 3. A resident of the zip code for the previous 12 months. If all inclusion criteria were met and the potential participant was interested in participating in the study, a consent form was mailed for review prior to the start of the study. The study was approved by the Institutional Review Board of the Harvard School of Public Health.

\section{Concept mapping methodology}

Concept mapping is a mixed methods approach originally used in program evaluation [36] but has since been used in the social sciences for examining other complex phenomena. Concept mapping studies have explored a variety of topic areas including the relationship between neighborhoods and mental health [37] and perceptions of neighborhood influences on health among immigrant populations [38]. The concept mapping process includes six steps: 1) Preparation, 2) Brainstorming, 3) Sorting and rating, 4) Data Analysis, 5) Interpretation, and 6) Utilization of concept maps. The concept mapping process has been extensively described in the literature $[29,35,39,40]$. For this study, the six steps of the concept mapping process occurred over a period of three nonconsecutive days. We conducted three concept mapping sessions in each of the four zip codes with the same participants in each session. Since each session built on the participant discussions during the previous sessions, we asked participants to attend all three sessions conducted in their respective zip code. Sixty-seven participants completed the concept mapping process. There was no loss to follow-up over the three sessions. Thirty-five participants were residents of the food desert and 32 from the food oasis.

Day 1: Brainstorming Session - During this $2 \mathrm{~h}$ session, we asked participants to freely generate words or short phrases in response to the focus statement: "What things, good or bad, influence your food buying practices?" We defined the phrase "food buying practices" as "where you buy food, the types of food you buy, and when you buy food." Participants responded to the focus statement using a round-robin approach. After an exhaustive list was generated, participants went through the list to consolidate statements they thought were too similar or overlapping. For example, participants consolidated the statements "billboards" and "food advertisement" into the statement "advertisements." Participants received a $\$ 20$ gift card for completing this session.

Day 2: Sorting and Rating Session - Participants returned for the second session 3 weeks after the first concept mapping session (brainstorming session). Each participant received a stack of note cards with a unique statement generated during the previous brainstorming session written on each card. Participants worked independently to sort the cards into piles that "make sense to you." After sorting the cards, participants assigned each pile a label or name that represented the contents of the pile. For example, one participant may have sorted the statements "fuel perks (gas discount)," "what stores are near where I live," "T-Accessible (public transportation)," and "gypsy cabs (unlicensed taxis)" into the same pile and labeled the pile "Transportation." A second activity was to rate how important each statement was to influencing food buying practices according to a Likert scale ( 1 = not at all important to $5=$ extremely important). Participants received a $\$ 25$ gift card for completing this session.

Day 3: Interpretation Session - Two weeks after the second concept mapping session, the same participants returned to interpret the concept maps generated in the 
second session. In small groups, participants were given flip chart paper and markers and asked to diagram how the statements generated within a cluster influenced food buying practices. In other words, participants were asked to generate a visual depiction of how the statements influenced food buying practices. Participants received a $\$ 30$ gift card for completing this session. For attending all three sessions, participants received a total of $\$ 75$ in gift cards.

\section{Data analysis}

We undertook three main analyses. First, we entered results from the sorting and rating step into specialized software, Concept Systems, Inc. [41] for analysis. A benefit to using Concept Systems software is that data are entered and analyzed in real time while participants complete other study activities. The second analysis utilized multidimensional scaling which took individual data across all participants and using a similarity matrix noted similarities and dissimilarities in how the data were sorted. An aggregate group product was produced in the form of a point map. A point map visually depicts how each statement was sorted with respect to the other statements for the entire group thereby incorporating each participant's sort data. Each point on the point map represents one of the unique statements generated during the brainstorming session. Points that are in close proximity were sorted more frequently by participants compared to points that are further apart.

The third analysis, hierarchical cluster analysis, partitioned the point map into clusters representing unique concepts or ideas. The final number of clusters selected was identified by participants as the appropriate number of clusters that represented their perceptions of factors that influence their food buying practices. Another type of concept map produced, a pattern match, is a ladder graph representation that allows comparisons to be made between groups. A horizontal rung of the ladder corresponds to a perfect correlation between the two groups being compared. For this study, a comparison was made between participants of the food desert and participants of the food oasis. A Pearson product-moment correlation was calculated to represent the correlation between the two groups.

\section{Results}

\section{Participant characteristics}

The sample consisted of 67 participants. The median age was 47 years. The sample was predominantly female (56.7\%) and African American (67.2\%). More than half of the sample did not own a personal car and found it difficult to find a ride (52.2\%). Table 1 displays additional participant characteristics.
Table 1 Participant Characteristics by Food Desert Status

\begin{tabular}{|c|c|c|c|}
\hline Zip code characteristic & Food desert & Food oasis & Total \\
\hline Total number of participants (\%) & $35(52.2)$ & $32(47.8)$ & 67.0 \\
\hline \multicolumn{4}{|l|}{ Age } \\
\hline Median age (years) & 47.0 & 47.3 & 47.0 \\
\hline Range & $28-66$ & $32-61$ & $28-66$ \\
\hline \multicolumn{4}{|l|}{ Sex $-n(\%)$} \\
\hline Male & $15(42.9)$ & $14(43.8)$ & $29(43.3)$ \\
\hline Female & $20(57.1)$ & $18(56.2)$ & $38(56.7)$ \\
\hline \multicolumn{4}{|l|}{ Race \& Ethnicity - n (\%) } \\
\hline African American & $20(57.1)$ & $25(78.1)$ & $45(67.2)$ \\
\hline Caucasian & $9(25.7)$ & $2(6.3)$ & $11(16.4)$ \\
\hline Hispanic/Latino & $3(8.6)$ & $2(6.3)$ & $5(7.5)$ \\
\hline Other & $3(8.6)$ & $3(9.4)$ & $6(8.9)$ \\
\hline \multicolumn{4}{|l|}{ Car ownership } \\
\hline $\begin{array}{l}\text { Do not own car \& hard } \\
\text { to find a ride }\end{array}$ & $18(51.4)$ & $17(53.1)$ & $35(52.2)$ \\
\hline $\begin{array}{l}\text { Do not own car \& able } \\
\text { to find a ride }\end{array}$ & $9(25.7)$ & $10(31.3)$ & $19(28.4)$ \\
\hline Own car & $8(22.9)$ & $5(15.6)$ & $13(19.4)$ \\
\hline \multicolumn{4}{|l|}{ Nearest bus stop - n (\%) } \\
\hline$<1$ block & $10(28.6)$ & $14(43.8)$ & $24(35.8)$ \\
\hline $1-2$ blocks & $12(34.3)$ & $5(15.6)$ & $17(25.4)$ \\
\hline 3-4 blocks & $8(22.9)$ & $8(25.0)$ & $16(23.9)$ \\
\hline 5 or more blocks & $5(14.2)$ & $5(15.6)$ & $10(14.9)$ \\
\hline \multicolumn{4}{|l|}{$\begin{array}{l}\text { Number of different bus routes } \\
\text { near home }-\mathrm{n}(\%)\end{array}$} \\
\hline $1-2$ routes & $16(45.7)$ & $17(53.1)$ & $33(49.2)$ \\
\hline $3-4$ routes & $9(25.7)$ & $8(25.0)$ & $17(25.4)$ \\
\hline 5 or more routes & $10(28.6)$ & $7(21.9)$ & $17(25.4)$ \\
\hline \multicolumn{4}{|l|}{ Bus frequency - n (\%) } \\
\hline$<15$ minutes & $9(25.7)$ & $10(31.3)$ & $19(28.4)$ \\
\hline Every $15-30$ minutes & $17(48.6)$ & $16(49.9)$ & $33(49.3)$ \\
\hline Every $30-45$ minutes & $6(17.1)$ & $3(9.4)$ & $9(13.4)$ \\
\hline$>45$ minutes & $3(8.6)$ & $3(9.4)$ & $6(8.9)$ \\
\hline
\end{tabular}

The two food deserts generated 110 and 182 unique or non-overlapping statements. The two food oases generated 147 and 171 unique statements. All of the statements generated from the four groups were combined into one list. Participants engaged in a process of removing duplicate entries and consolidating similar statements to generate a final master list. The final master list included 163 unique or non-overlapping statements. Examples of unique statements included in the final master list were "appearance of food," "brand names," "ease of theft," "microwaveable foods" and "preference." The 163 statements were partitioned into 8 clusters. Participants were initially presented with a 12 cluster solution map. Participants stated that the 12 clusters, or 
unique concepts were overlapping and did not accurately reflect their perceptions. After using the specialized software to decrease the number of clusters, we presented a final 8 cluster solution map agreed upon and named by participants. Figure 1 illustrates the point cluster map with the names of each cluster given by participants. Statement numbers represented as points on the map presented in Figure 1 can be linked to Table 2 to identify the exact statement name. Overlapping points on the map illustrate areas with a high degree of agreement in participant perceptions of the relationship between statements. It may appear that specific statements do not fit into a certain cluster. Two explanations can be offered to address this seemingly inconsistency. First, the way participants perceived the statement influenced how the statements were sorted together. Second, statements participants perceived as not fitting nicely into one pile may have been sorted with other statements that were considered "leftovers." However, it is important to note that a spanning analysis, a type of analysis used to identify how statements were sorted relative to other statements, were performed to explore these inconsistencies. The results (figures not shown) suggest that participants were consistent in how these statements were sorted, thereby suggesting a perspective based on lived experiences outside the understanding of the researchers.

\section{Average cluster and statement ratings}

Participants rated how important each statement was to influencing food buying practices on a scale of 1 (not at all important) to 5 (extremely important) during the sorting and rating step of the concept mapping process. Table 2 outlines the average statement and cluster ratings. The table is organized by cluster with the cluster name in bold type. Underneath each cluster label are the statements that comprised that cluster. The number besides each statement label (in parenthesis) represents the statement number that can be used to link each statement with the location on the point cluster map (Figure 1). The two columns next to the cluster label and corresponding statements present the average cluster ratings for participants of the food deserts and food oases. In other words, these columns present the degree of importance of each statement in influencing food buying practices.

Ratings were then grouped into tertiles. Tertile values are based on the degree to which each statement influenced food buying practices and designated as low (1.292.50), moderate (2.51-3.72) and high (3.73-4.93). For example, the cluster Health Consciousness received an average rating of 3.71 (moderately important for influencing food buying practices) for food desert participants and 4.07 (highly important for influencing food buying practices) for food oasis participants. Overall, the average cluster ratings were similar for residents of the food deserts and food oases. The clusters Health Consciousness, Personal Decisions and Shopping Concerns, were rated higher by participants from the food oases compared to residents of the food deserts. This suggests that food oasis participants perceived the statements within these clusters as more important to influencing food buying practices compared to residents of the food deserts.

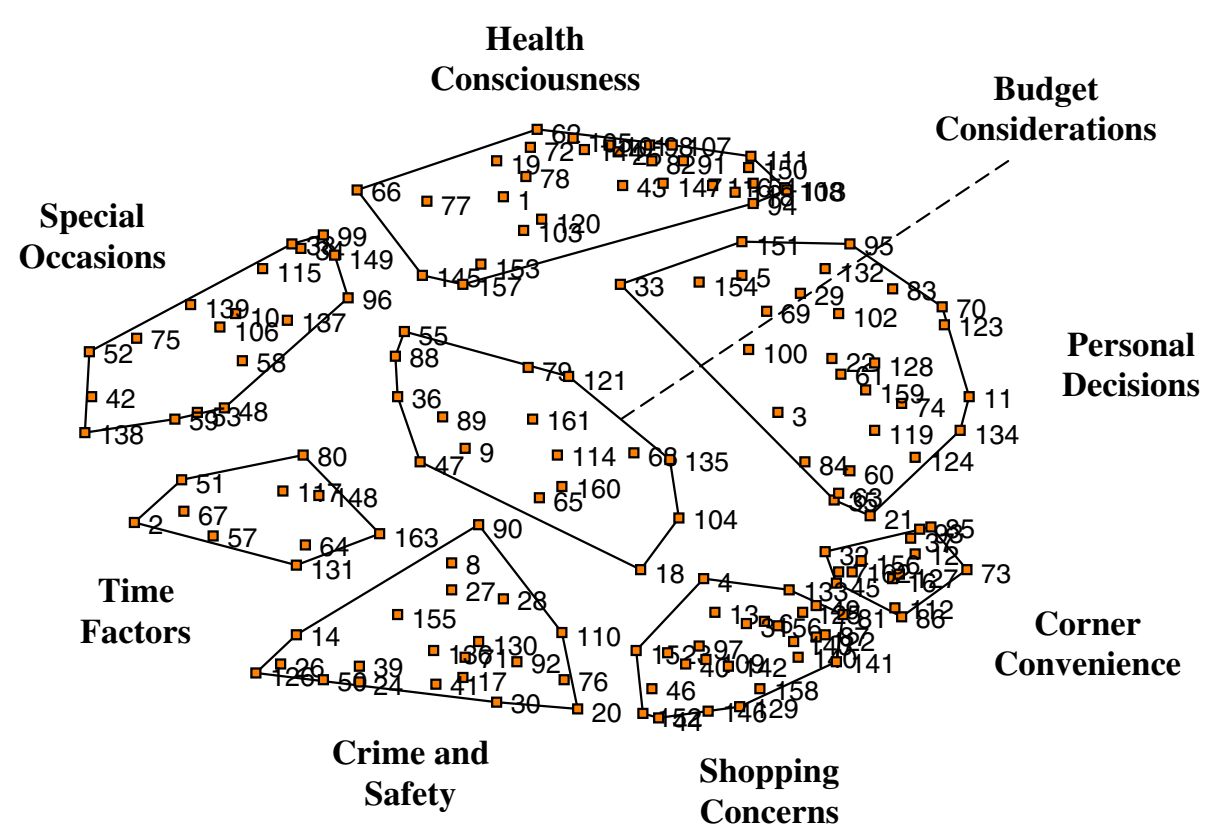

Figure 1 Point Cluster Map of a 8-Cluster Solution. 
Table 2 Average Cluster and Statement Ratings by Food Desert Status

\begin{tabular}{|c|c|c|c|c|c|}
\hline \multirow[t]{2}{*}{$\begin{array}{l}\text { Cluster Name and Statements } \\
\text { (Statement ID Number) }\end{array}$} & \multicolumn{2}{|c|}{$\begin{array}{l}\text { Influences Food } \\
\text { Buying Practices }\end{array}$} & \multirow[t]{2}{*}{$\begin{array}{l}\text { Cluster Name and Statements } \\
\text { (Statement ID Number) }\end{array}$} & \multicolumn{2}{|c|}{$\begin{array}{l}\text { Influences Food } \\
\text { Buying Practices }\end{array}$} \\
\hline & Food Desert & Food Oasis & & Food Desert & Food Oasis \\
\hline HEALTH CONSCIOUSNESS & Moderate & High & PERSONAL DECISIONS & Moderate & High \\
\hline Taste (147) & High & High & Freshness (70) & High & High \\
\hline Knowing how to cook (94) & High & High & Cost (35) & High & High \\
\hline How food is prepared (82) & High & High & What your needs are (159) & High & High \\
\hline Personal health (116) & High & High & Appearance of food (11) & High & High \\
\hline Portion size (118) & High & High & Quality (123) & High & High \\
\hline Food preparation time (66) & High & High & Food handling (63) & High & High \\
\hline High cholesterol (78) & High & High & Labels (95) & High & High \\
\hline Ingredients in food (91) & High & High & Quantity of items (124) & High & High \\
\hline Texture of food (150) & High & High & Preference (119) & High & High \\
\hline More health conscious (107) & High & High & How food is stored (83) & High & High \\
\hline Eating balanced meals (54) & High & High & Seasonings I need to cook with (132) & High & High \\
\hline Nutritional content (111) & High & High & How much I can carry (84) & High & High \\
\hline Natural food (108) & Moderate & High & Making food stretch (102) & High & High \\
\hline A lot of sodium in foods (1) & Moderate & High & Samples (128) & Moderate & High \\
\hline Fat content (62) & High & High & $\begin{array}{l}\text { The cost of eating healthy } \\
\text { makes me buy less (151) }\end{array}$ & Moderate & High \\
\hline Sugar content (144) & High & High & Farmer's markets (61) & High & High \\
\hline Diet (43) & High & High & Buy in bulk (21) & Moderate & High \\
\hline Calorie intake (25) & High & High & Freezer space (69) & Moderate & High \\
\hline What foods make you tired (157) & Moderate & High & $\begin{array}{l}\text { Cook large quantities and eat } \\
\text { for the week (33) }\end{array}$ & High & High \\
\hline Losing weight (98) & High & High & $\begin{array}{l}\text { Able to cook large quantities to } \\
\text { last a few days (5) }\end{array}$ & Moderate & High \\
\hline Healthy eating is too difficult (77) & Moderate & High & Family-sized packages (60) & Moderate & High \\
\hline Organic foods (113) & Moderate & High & Grocery lists (74) & High & Moderate \\
\hline Genetically modified foods (72) & Moderate & Moderate & $\begin{array}{l}\text { Cheaper to cook than eat at fast } \\
\text { food restaurants (29) }\end{array}$ & High & Moderate \\
\hline $\begin{array}{l}\text { Modify prepared foods so } \\
\text { healthier (105) }\end{array}$ & Moderate & Moderate & Variety of prepared food (154) & Moderate & Moderate \\
\hline $\begin{array}{l}\text { Break down large quantities into } \\
\text { smaller servings (19) }\end{array}$ & High & Moderate & Able to buy ethnic foods (3) & Low & Moderate \\
\hline $\begin{array}{l}\text { Make your own foods instead of foods } \\
\text { in a jar (101) }\end{array}$ & Moderate & Moderate & Shop everyday to have fresh food (134) & Low & Moderate \\
\hline Use of food with medications (153) & High & Moderate & Buy packaged food and jazz it up (22) & Moderate & Moderate \\
\hline Processed foods (120) & Low & Moderate & Make weekly menus (100) & Moderate & Moderate \\
\hline Microwaveable foods (103) & Moderate & Moderate & & & \\
\hline $\begin{array}{l}\text { Supplement cooked food with } \\
\text { restaurant food (145) }\end{array}$ & Moderate & Moderate & & & \\
\hline $\begin{array}{l}\text { Supplement cooked food with } \\
\text { restaurant food (145) }\end{array}$ & Moderate & Moderate & & & \\
\hline TIME FACTORS & Moderate & Moderate & SPECIAL OCCASIONS & Moderate & Moderate \\
\hline Food recalls (67) & High & High & Lifestyle (96) & High & High \\
\hline Expiration date (57) & High & High & Family upbringing (59) & Moderate & High \\
\hline Household preference (80) & Moderate & High & Family influence (58) & Moderate & High \\
\hline Season (131) & Moderate & High & Loss of appetite (99) & Moderate & High \\
\hline
\end{tabular}


Table 2 Average Cluster and Statement Ratings by Food Desert Status (Continued)

\begin{tabular}{|c|c|c|c|c|c|}
\hline Food Industry (64) & High & Moderate & Mood swings (106) & Moderate & High \\
\hline Television (148) & Moderate & Moderate & Guests/Company (75) & Moderate & High \\
\hline Word of mouth (163) & Moderate & Moderate & Special occasions (139) & Moderate & High \\
\hline Pets need to eat (117) & Moderate & Moderate & $\begin{array}{l}\text { Don't go shopping when } \\
\text { you're hungry (48) }\end{array}$ & Moderate & High \\
\hline $\begin{array}{l}\text { Easier to buy at fast food } \\
\text { restaurants (51) }\end{array}$ & Low & Moderate & Participation in research studies (115) & High & High \\
\hline \multirow{9}{*}{$\begin{array}{l}\text { A treat is eating at a high } \\
\text { end restaurant ( } 2 \text { ) }\end{array}$} & Low & Moderate & Cravings (38) & Moderate & Moderate \\
\hline & & & Temptation (149) & Moderate & Moderate \\
\hline & & & Cooking fatigue (34) & Moderate & Moderate \\
\hline & & & Depression (42) & Moderate & Moderate \\
\hline & & & Easier to buy ready-made food (52) & Low & Moderate \\
\hline & & & Social circles (138) & Moderate & Moderate \\
\hline & & & $\begin{array}{l}\text { Eating at restaurants make me buy } \\
\text { less at stores (53) }\end{array}$ & Low & Moderate \\
\hline & & & Anxiety (10) & Moderate & Moderate \\
\hline & & & Short lunch period, so I eat fast foods (137) & Low & Moderate \\
\hline CRIME AND SAFETY & Moderate & Moderate & BUDGET CONSIDERATIONS & Moderate & Moderate \\
\hline Inflation (90) & High & High & Income (89) & High & High \\
\hline Amount of money you have to spend (8) & High & High & Education (55) & High & High \\
\hline Being overcharged repeatedly (17) & High & High & $\begin{array}{l}\text { When you get your Social Security } \\
\text { check (161) }\end{array}$ & High & High \\
\hline Schedule (130) & High & High & Food pantries (65) & Moderate & High \\
\hline Rodents are common around food (126) & High & High & Household composition (79) & Moderate & High \\
\hline Bad experiences (14) & Moderate & High & Dollar menus (47) & Moderate & High \\
\hline Weather (155) & High & Moderate & $\begin{array}{l}\text { Minimum purchase required for } \\
\text { using certain payment (104) }\end{array}$ & Moderate & High \\
\hline $\begin{array}{l}\text { No one-stop shopping in } \\
\text { "the hood" (110) }\end{array}$ & Moderate & Moderate & When you get food stamps (160) & Moderate & Moderate \\
\hline Buy 2 get $\$ 1$ off can be a trick (20) & Moderate & Moderate & Professional recommendation (121) & Moderate & Moderate \\
\hline Items without a price tag (92) & Low & Moderate & Brand names (18) & Moderate & Moderate \\
\hline Cheaper foods in the suburbs (28) & Moderate & Moderate & Impulse (88) & Moderate & Moderate \\
\hline Customers get into fights (41) & Moderate & Moderate & $\begin{array}{l}\text { Anticipating what food pantry will } \\
\text { distribute (9) }\end{array}$ & Moderate & Moderate \\
\hline Crime (39) & High & Moderate & Overwhelmed by options (114) & Moderate & Moderate \\
\hline Gypsy cabs (76) & Low & Moderate & $\begin{array}{l}\text { Food trucks on the side of the } \\
\text { road have fresh and cheap food (68) }\end{array}$ & Moderate & Moderate \\
\hline Celebrity endorsements (27) & Low & Moderate & Country where food is made (36) & Low & Moderate \\
\hline Fuel perks (71) & Moderate & Moderate & Shopping when tired (135) & Low & Moderate \\
\hline Cab fare (24) & Moderate & Moderate & & & \\
\hline Shopping with kids or grandkids (136) & Low & Low & & & \\
\hline Child care at the store (30) & Low & Low & & & \\
\hline Ease of theft (50) & Low & Low & & & \\
\hline $\begin{array}{l}\text { Can steal under } \$ 250 \text { without being } \\
\text { arrested (26) }\end{array}$ & Low & Low & & & \\
\hline SHOPPING CONCERNS & Moderate & High & CORNER CONVENIENCE & High & High \\
\hline Store crowding (142) & High & High & Good sanitation at the meat counter (73) & High & High \\
\hline Store cleanliness (141) & High & High & Availability of food (12) & High & High \\
\hline
\end{tabular}


Table 2 Average Cluster and Statement Ratings by Food Desert Status (Continued)

\begin{tabular}{|c|c|c|c|c|c|}
\hline Double coupons (49) & High & High & Discount card (45) & High & High \\
\hline T-Accessible (146) & Moderate & High & Bargains (16) & High & High \\
\hline Distance (46) & High & High & Sales (127) & High & High \\
\hline What stores are near where I live (158) & High & High & Know what to buy at different stores (93) & High & High \\
\hline Scent of store (129) & High & High & How neat the store is (86) & & \\
\hline Store hours (143) & High & High & One-stop shopping (112) & Moderate & High \\
\hline Transportation (152) & High & High & Coupons (37) & High & High \\
\hline Enough cashiers (56) & High & High & Convenience (32) & High & High \\
\hline Reputation of store (125) & High & High & Where gift cards are for (162) & High & High \\
\hline Customer service (40) & High & High & How much time I have to shop (85) & High & High \\
\hline Availability of sale items (13) & High & High & What can fit in the shopping cart (156) & Moderate & High \\
\hline $\begin{array}{l}\text { How comfortable you feel at the } \\
\text { store ( } 81)\end{array}$ & High & High & Amount gift cards are for (7) & High & High \\
\hline $\begin{array}{l}\text { Different locations have different } \\
\text { prices and selection (44) }\end{array}$ & High & High & & & \\
\hline Long lines (97) & Moderate & High & & & \\
\hline Neighborhood of the store (109) & Moderate & High & & & \\
\hline Circulars (31) & High & Moderate & & & \\
\hline Advertisements (6) & Moderate & Moderate & & & \\
\hline $\begin{array}{l}\text { Stop \& Shop and Shaw's } \\
\text { have different departments (140) }\end{array}$ & Moderate & Moderate & & & \\
\hline $\begin{array}{l}\text { How well you know the layout of } \\
\text { the store ( } 87 \text { ) }\end{array}$ & High & Moderate & & & \\
\hline Promotions (122) & High & Moderate & & & \\
\hline Self check-out (133) & Moderate & Moderate & & & \\
\hline Bag your own groceries (15) & Low & Moderate & & & \\
\hline Buying grocery bags (23) & Low & Low & & & \\
\hline Able to buy religious foods (4) & Low & Low & & & \\
\hline
\end{tabular}

Note: The 163 statements are presented within their clusters (capitalized and bolded) and the parenthetical numbers refer to the actual statement number and can be used to link the table information to Figure 1. The numbers do not have any substantive meaning. Ratings represent how strongly each statement influences food buying practices. Ratings between 1.29-2.50 are designated low, 2.51-3.72 designated moderate and 3.73-4.93 designated high.

Figure 2 presents a pattern match, a ladder graph representation which illustrates differences in average cluster ratings between food desert and food oasis participants. The vertical black line on the left represents average cluster ratings for food desert participants. The vertical black line on the right represents average cluster ratings for food oasis participants. The 3.07 at the bottom of this line and the 4.2 at the top represent the lowest and highest cluster ratings respectively. These ratings reflect the possible 1 (not at all important) to 5 (extremely important) rating scale participants used to assess how important each statement and subsequent cluster was to influencing food buying practices.

A horizontal rung of the ladder depicts a perfect correlation between the food desert and oasis groups, nearly seen with the cluster Corner Convenience. The cluster rating by food desert participants was 4.10 and 4.20 by food oasis participants (ratings not shown). This suggests that both groups perceive the statements within the cluster Corner Convenience similarly and as being extremely important to influencing food buying practices. Although the pattern match illustrates similar cluster ratings between the two groups, the average cluster ratings for the food oasis participants were slightly higher. The average cluster ratings and rankings are presented in Table 3 . Not only were average cluster ratings similar, but 6 of the 8 clusters have the same rankings for both groups. This finding suggests that both groups perceive the relative order and the degree of importance of each cluster similarly. The Pearson product moment correlation of $\mathrm{r}=0.93$ at the bottom of the figure represents the correlation between average cluster ratings for all clusters for food desert and food oasis participants. In other words, the correlation of 0.93 suggests that the average cluster ratings are highly correlated between the two groups. 


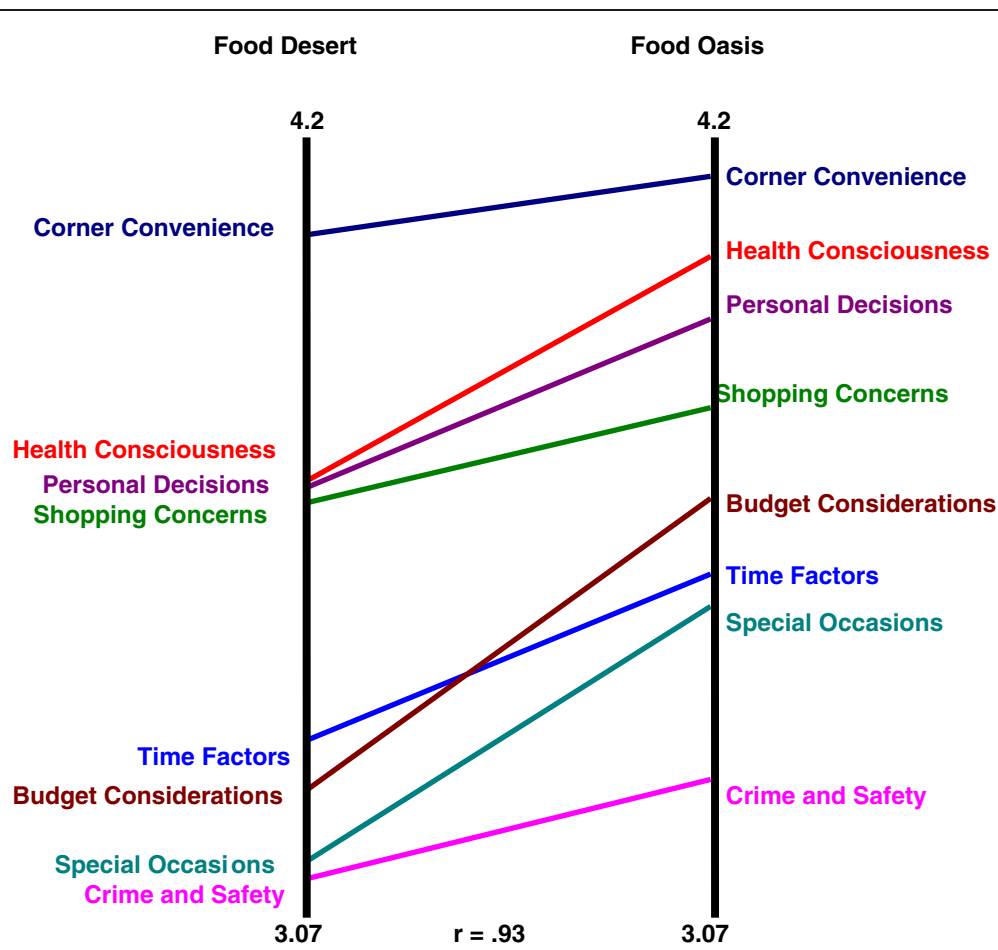

Figure 2 Pattern Match Comparing Factors that Influence Food Buying Practices between Participants from the Food Desert and Food Oasis*. "The two vertical lines represent average cluster ratings with results for food desert participants on the left and food oasis participants on the right.

Statements generated by both food desert and food oasis participants were noted. Examples included "buy in bulk," "cravings," "farmer's markets," "family influence," "organic foods," "quality," "rodents are common around food," "store cleanliness," "taste," "store hours," "food pantries," and "able to buy ethnic foods." However, few statements unique to each group were documented. Examples of statements unique to food desert participants were "pets need to eat," "how much I can carry," "making food stretch," "food recalls," and "labels." Unique statements generated by residents from the food oases included "crime," "ease of theft," "use of food with medications," "24 h stores," "dollar menus," and "long lines."

Table 3 Average Cluster Ratings for Food Desert and Food Oasis Participants

\begin{tabular}{ccc}
\hline Cluster name & Food desert rating & Food oasis rating \\
\hline Health Consciousness & 3.71 & 4.07 \\
Personal Decisions & 3.70 & 3.97 \\
Time Factors & 3.29 & 3.56 \\
Special Occasions & 3.10 & 3.51 \\
Crime and Safety & 3.07 & 3.23 \\
Budget Considerations & 3.21 & 3.68 \\
Shopping Concerns & 3.68 & 3.83 \\
Corner Convenience & 4.10 & 4.20 \\
\hline
\end{tabular}

\section{Cluster interpretation}

The interpretation step of the concept mapping process involved delving deeper into how statements within a cluster were related to each other and how they related back to the focus statement of influencing food buying practices. Participants were divided into smaller groups of 3-4 people and asked to diagram the pathways in which statements within a cluster influence food buying practices. Small groups were asked to illustrate visually how the statements were inter-related. One group diagramed the statements being related using a flow chart. Another group used shapes such as arrows, circles and squares, in a feedback loop, to illustrate how they perceived the clusters being related in influencing food buying practices. The clusters Corner Convenience (Figure 3) and Time Factors (Figure 4) were selected for interpretation. Clusters that comprise statements that were not easily understood were selected for the in-depth explanation.

\section{Corner convenience}

Corner Convenience was the highest rated cluster for both food desert and food oasis participants. Food desert participants emphasized the statement "one stop shopping" as the central statement within the cluster Corner Convenience. As this group stated: 


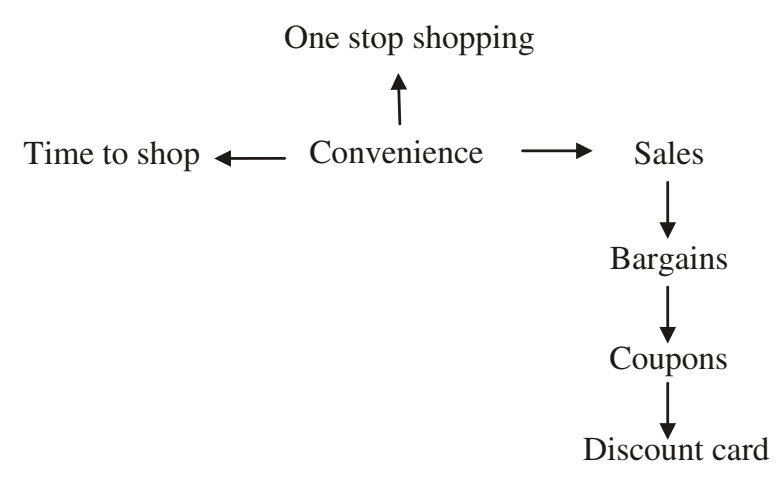

Figure 3 Interpretation of the Cluster Corner Convenience by select food desert participants.

"One stop shopping is important for a group that is missing here, which are men. Guys usually just go to the supermarket and get everything they need, and they don't generally go to farmer's markets or specialty stores unless they have to buy a birthday cake or something like that. Even then they go to supermarkets."

While the statement "one-stop shopping" was described as being the key factor during the interpretation step, this was not reflected in the average statement ratings. "One-stop shopping" was one of two statements within the cluster perceived as moderately important to influencing food buying practices by residents of the food desert. The other 12 statements within the cluster were perceived as being extremely important to influencing food buying practices. In other words, average statement ratings showed statements such as "sales," "discount card," "bargains," and "availability of food" as more important than the notion of "one-stop shopping."

\section{Time factors}

The cluster Time Factors was the fifth highest rated cluster for food desert participants and the sixth highest rated cluster among food oasis participants. Residents of the food oasis focused on the statement "television" as the key factor in how the statements within the cluster Time Factors influence food buying practices. This group explained:

"Advertising always embeds thoughts into your mind. It's like Doritos and Popeyes [Chicken] sometimes advertise and that gets stuck in your head. I know that's not healthy eating, but I have a craving for it thanks to my television and the advertising companies behind it."

Figure 4 illustrates how select food oasis participants perceive the inter-relationship between the statements that comprise the cluster Time Factors and how the statements contribute to the consumption of unhealthy foods.

\section{Discussion}

In this study, we explored factors influencing food buying practices among residents of food deserts and oases in Boston. We identified a range of factors that influenced food buying practices, determined the inter-relationship of each factor, and illustrated the

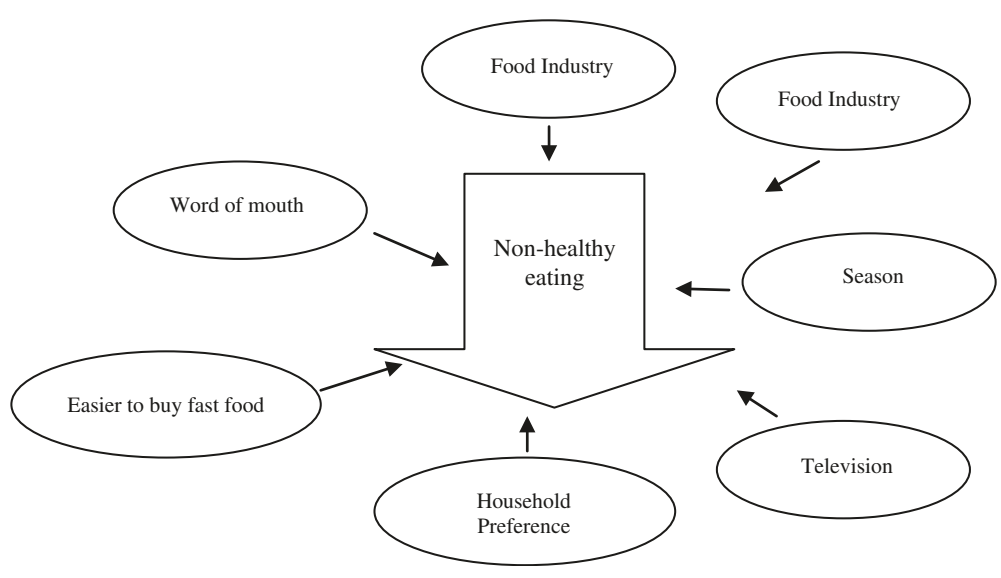

Figure 4 Interpretation of the cluster Time Factors by select food oasis participants. 
pathways. As noted in the Results section, few statements unique to each group (food desert versus food oasis) were identified. Our findings also suggest that few differences in food buying practices among study participants exist regardless of food desert status. One difference was presented by participants residing in the food deserts who explained the statement "how much I can carry." Participants expressed restrictions in the quantity of food purchased due to the inability to carry heavy bags. Participants explained a reliance on public transportation and difficulty carrying bags on trains and buses and having to walk home from bus stops.

Another difference is in the explanation of the statement "24-hour stores" generated by participants in the food oases. Participants described how the presence of 24-hour stores in their neighborhoods influences food buying practices. Participants who were shift workers described purchasing food from these venues after work as these are the only establishments open in their neighborhood. The purchased food was inevitably energy dense given the availability of nutrient rich foods offered at convenience stores and fast food restaurant drive-throughs [a type of service that allows customers to obtain food without leaving their vehicle] that are open 24-hours each day in the selected neighborhoods.

A novel statement identified that has not been described extensively in the literature was "making food stretch." Participants of the food deserts described how their desire and intent to make food last longer influenced their food buying practices. For example, some participants received only one paycheck per month, leading to food purchasing on a monthly basis. They bought items that could be broken down into smaller quantities (e.g. packaged meat) for multiple meals, modified by watering down (e.g. sauces), or supplemented by food pantry items.

Another behavior that is not discussed widely in the literature pertains to the statements "crime" and "ease of theft." These statements, identified by participants in the food oases, were mentioned in the context of fights that erupt in the stores while shopping, crime within neighborhoods, and weighing the risks of stealing when there is not enough money or food vouchers to obtain food. Participants stated that at some supermarkets, patrons could steal up to $\$ 250$ without being arrested if caught. The disclaimer was that a patron would be arrested if found on the premises after being caught stealing. This was discussed as a viable option for those willing to take the risk.

Existing studies have used either quantitative or qualitative methods to explore facilitators and barriers to healthy eating and food choice. Examples of statements identified that are consistent with those documented in the literature pertained to convenience of getting to the store, store hours, and one-stop shopping [42]; utilizing coupons, or discount vouchers, to defray the cost of a food item [19], having a fixed income has been cited extensively as a factor involved in food buying practices [43]; availability of food [44]; cost of food [17,23]; and transportation options to and from food stores $[45,46]$.

Our findings are in contrast to a study previously conducted by Walker et al. in Pittsburgh, PA [19]. Findings from this study showed that compared to residents of a food oasis, residents of a food desert perceived some factors as more important to influencing food buying practices. The types of factors identified by food desert participants included survival, mental health, and macrolevel factors for food desert participants. Food oasis participants uniquely identified conveniences of the food environment and available social service resources [19].

By contrast in Boston, we found few differences in perceptions of factors influencing food buying practices according to food desert status as shown with the pattern match and average cluster ratings (Figure 2). This suggests that food purchasing preferences are similar among residents of low income neighborhoods in Boston irrespective of neighborhood-level access to a supermarket. Additionally, food desert and food oasis participants focused on the importance of emergency food assistance programs. This is consistent to findings from Eikenberry and Smith who found that a promoter of healthy eating among low-income residents was the utilization of federal or local food assistance programs [17]. In our study, participants from both the food deserts and oases used emergency food assistance programs regularly. Participants outlined how they navigated the system of frequenting food pantries and soup kitchens daily. The high dependence and utilization (64.4\% of participants) of these resources may account for the observed similarities in average cluster ratings and high correlation coefficient $(r=0.93)$ However, it can be argued that daily use is no longer considered "emergency" services, but rather chronic use of these resources. Additional studies are needed to implement and evaluate successful city-specific programs that minimize the effects of poor food access to determine how these programs can be adapted to other cities.

A strength of this study was the use of Concept Mapping as the methodology, which is an innovative mixed methods approach to assess residents' preferences and perceptions. Unlike other qualitative methods such as focus groups or in-depth interviews, concept mapping allows for the inter-relationships between statements to be identified and quantified. These relationships can be used for further theorizing how different factors play a role in influencing food buying practices. A second strength of this study is that we incorporated 4 low-income neighborhoods in a large, urban city. 
Limitations of this study were similar to limitations found in qualitative studies, specifically sample size and generalizability. With 67 participants in the study, we are unable to generalize to other food deserts or non low-income food deserts. However, our goal was not to generalize, but to explore perceptions of factors influencing food buying practices so that hypotheses could be generated. Defining a food desert as an area without a supermarket within 0.5 miles of the center of the zip code presents another limitation. Using this definition, a participant could reside in a food desert but live within 0.5 miles of a supermarket in an adjacent zip code, thereby having access to a supermarket. Given the limited resources for this study, we were unable to assess for each potential participant individualized measures of access during participant recruitment. This enhanced method may prove beneficial in a future study. Improved techniques for characterizing areas with differential supermarket access is warranted to provide better agreement in the literature on what constitutes a food desert.

\section{Conclusions}

This study sought to explore food buying practices among low-income residents with differential supermarket access. City-specific measures offered through social service agencies may improve access to foods for residents with poor supermarket access. As a result, food buying practices between residents with and without supermarket access may appear similar. Understanding the availability and utilization of resources within a city that are potentially beneficial to improving food access can help in identifying policies and interventions that can be developed to ultimately promote healthy eating practices.

\section{Competing interests}

The authors declare that they have no competing interests.

\section{Acknowledgements}

This research was funded by the Robert Wood Johnson Foundation Health and Society Scholars seed grant program.

\footnotetext{
Author details

${ }^{1}$ Department of Society, Human Development and Health, Harvard School of Public Health, 401 Park Drive, Room 445-C, Boston, MA 02215, USA.

${ }^{2}$ University of Wisconsin-Milwaukee, Joseph J. Zilber School of Public Health, Alumni House 327, P.O. Box 413, Milwaukee, WI 53201-0413, USA.

${ }^{3}$ Department of Population Medicine, Harvard Medical School, 133 Brookline Avenue, 3rd Floor, Boston, MA 02215, USA. ${ }^{4}$ Department of Society, Human Development, and Health, Harvard University School of Public Health, 677 Huntington Avenue, Boston, MA 02115, USA.
}

\section{Authors' contributions}

REW, JB and IK contributed to the conception and design of the study. REW facilitated recruitment of participants and was responsible for data collection. JB and IK contributed to questionnaire design. REW and IK drafted the manuscript. All authors read and approved the final version of the final paper.
Received: 13 August 2011 Accepted: 10 April 2012

Published: 10 April 2012

\section{References}

1. Maddock J: The relationship between obesity and the prevalence of fast food restaurants: state-level analysis. Am J Health Promot 2004, 19:137-143.

2. Inagami S, Cohen DA, Kinch BK, Asch SM: You are where you shop: grocery store locations, weight, and neighborhoods. Amer J Prev Med 2006, 31:10-17.

3. Morland K, Diez Roux A, Wing S: Supermarkets, other food stores, and obesity: the atherosclerosis risk in communities study. Amer J Prev Med 2006, 30:333-339.

4. Morland KB, Evenson KR: Obesity prevalence and the local food environment. Health Place 2009, 15:491-495.

5. Furey S, Strugnell C, Mcllveen $\mathrm{H}$ : An investigation of the potential existence of "Food Deserts" in Rural and Urban Areas of Northern Ireland. Agr Human Values 2001, 18:447-457.

6. Walker RE, Keane CR, Burke JG: Disparities and access to healthy food in the United States: a review of food deserts literature. Health Place 2010, 16:876-884.

7. Forsyth AJM, Maclntyre S, Anderson A: Diets for disease? Intra-urban variation in reported food consumption in Glasgow. Appetite 1994, 22:259-274.

8. Shohaimi S, Welch A, Bingham S, Luben R, Day N, Wareham N, Khaw K: Residential area deprivation predicts fruit and vegetable consumption independently of individual educational level and occupational social class: a cross sectional population study in the Norfolk cohort of the European Prospective Investigation into Cancer (EPIC-Norfolk). J Epidemiol Community Health 2004, 58:686-691.

9. Cummins S, Macintyre S: Food environments and obesityneighbourhood or nation? Int J Epidemiol 2006, 35:100-104.

10. Laraia BA, Siega-Riz AM, Kaufman JS, Jones SJ: Proximity of supermarkets is positively associated with diet quality index for pregnancy. Prev Med 2004, 39:869-875.

11. Moore LV, Roux AVD, Nettleton JA, Jacobs DR: Associations of the local food environment with diet quality - a comparison of assessments based on surveys and geographic information systems. Am J Epidemiol 2008, 167:917-924.

12. Rose D, Richards R: Food store access and household fruit and vegetable use among participants in the US Food Stamp Program. Public Health Nutr 2004, 7:1081-1088.

13. Morland K, Wing S, Diez-Roux A: The contextual effect of the local food environment on residents' diet: the Atherosclerosis Risk in Communities Study. Am J Public Health 2002, 92:1761-1777.

14. Zenk SN, Schulz AJ, Hollis-Neely T, Campbell RT, Holmes N, Watkins G, Nwankwo R, Odoms-Young A: Fruit and vegetable intake in African Americans - income and store characteristics. Am J Prev Med 2005, 29:1-9.

15. Cheadle A, Psaty BM, Curry S, Wagner E, Diehr P, Koepsell T, Kristal A: Community-level comparison between the grocery store environment and individual dietary practices. Prev Med 1991, 20:250-261.

16. Walker R, Kawachi I: Race, ethnicity, and obesity. In The Oxford Handbook of the Social Science of Obesity. Edited by Cawley J. Oxford: Oxford University Press, Inc; 2011:257-275.

17. Eikenberry N, Smith C: Healthful eating: perceptions, motivations, barriers, and promoters in low-income minnesota communities. J Am Diet Assoc 2004, 104(7):158-1161.

18. Hendrickson D, Smith C, Eikenberry N: Fruit and vegetable access in four low-income food deserts communities in Minnesota. Agr Human Values 2006, 23:371-383.

19. Walker RE, Fryer C, Butler J, Keane C, Kriska A, Burke JG: Factors influencing food buying practices in residents of a low-income food desert and lowincome food oasis. JMMR 2011, 5(3):247-268.

20. Locher JL, Ritchie CS, Roth DL, Sen B, Vickers Douglas K, Vailas LI: Food choice among homebound older adults: motivations and perceived barriers. J Nutr Health Aging 2009, 13(8):659-664.

21. French SA, Shimotsu ST, Wall M, Gerlach AF: Capturing the spectrum of household food and beverage purchasing behavior: a review. J Am Diet Assoc 2008, 108:2051-2058.

22. Boyington JEA, Carter-Edwards L, Piehl M, Hutson J, Langdon D, McManus S: Cultural Attitudes Toward Weight, Diet, and Physical Activity Among Overweight African American Girls. Prev Chronic Dis 2008, 5(2):A36. 
23. Waterlander WE, deMul A, Schuit AJ, Seidell JC, Steenhuis IHM: Perceptions on the use of pricing strategies to stimulate healthy eating among residents of deprived neighbourhoods: a focus group study. Int J Behav Nutr Phys Act 2010, 7(1):44-55.

24. Gellar LA, Schrader K, Nansel TR: Healthy eating practices: perceptions, facilitators, and barriers among youth with diabetes. Diabetes Educat 2007, 33(4):671-679.

25. Bloemer J, de Ruyter $\mathrm{K}$ : On the relationship between store image, store satisfaction and store loyalty. Eur J Mark 1998, 32(5/6):499-513.

26. Carpenter JM, Moore M: Consumer demographics, store attributes, and retail format choice in the US grocery market. International Journal of Retail \& Distribution Management 2006, 34(6):434-452.

27. Grether ET: External Product and Enterprise Differentiation and Consumer Behavior. In Consumer Behavior and Motivation, Marketing Symporium. Edited by Cole RH. Urbana: University of Illinois; 1955.

28. Kane M, Trochim WMK: Concept Mapping for Planning and Evaluation. Thousand Oaks: Sage Publications; 2007.

29. Trochim W, Kane M: Concept mapping: an introduction to structural conceptualization in health care. Int J Qual Health Care 2005, 17(3):187191

30. Grubesic TH: Zip codes and spatial analysis: problems and prospects. Soc Econ Plann Sci 2008, 42:129-149.

31. Grubesic TH, Matisziw TC: On the use of ZIP codes and ZIP code tabulation areas (ZCTAs) for the spatial analysis of epidemiological data. Int J Heal Geogr 2006, 5:58-72.

32. Census 2000 ZIP code tabulation areas technical documentation. Available at http://www.census.gov/geo/ZCTA/zcta_tech_doc.pdf. Accessed January 2, 2012

33. Apparicio P, Cloutier M-S, Shearmur R: The case of Montreal's missing food deserts: evaluation of accessibility to food supermarkets. Int J Health Geogr 2007, 6(4).

34. Estabrooks PA, Lee RE, Gyurcsik NC: Resources for physical activity participation: does availability and accessibility differ by neighborhood socioeconomic status? Ann Behav Med 2003, 25(2):100-104.

35. Walker RE, Butler J, Kriska A, Keane C, Fryer CS, Burke JG: How does food security impact residents of a food desert and food oasis? J Hunger Environ Nutr 2010, 5(4):1-17.

36. Trochim W: An introduction to concept mapping for program planning and evaluation. Eval Program Plann 1989, 12:1-16.

37. O'Campo P, Salmon C, Burke J: Neighbourhoods and mental well-being: what are the pathways? Health Place 2009, 15(1):56-68

38. Haque N, Rosas S: Concept mapping of photovoices: sequencing and integrating methods to understand immigrants' perceptions of neighborhood influences on health. Fam Community Health 2010, 33 (3):193-206.

39. Burke J, O'Campo P, Salmon C, Walker R: Pathways connecting neighborhood influences and mental well-being: socioeconomic position and gender differences. Soc Sci Med 2009, 68:1294-1304

40. Burke J, O'Campo P, Peak G, Gielen A, McDonnell K, Trochim WMK: An introduction to concept mapping as a participatory public health research method. Qual Health Res 2005, 15(10):1392-1410.

41. Concept Systems, Inc., in Ithaca, NY; 2008.

42. Hampson SE, Martin J, Jorgensen J, Barker M: A social marketing approach to improving the nutrition of low-income women and children: an initial focus group study. Public Health Nutr 2009, 12(9):1563-1568.

43. Kelly LE, Patterson BJ: Childhood nutrition: perceptions of caretakers in a low-income urban setting. J Sch Nurs 2006, 22(6):345-351.

44. Turrell G, Bentley R, Thomas LR, Jolley D, Subramanian SV, Kavanagh AM: A multilevel study of area socio-economic status and food purchasing behaviour. Public Health Nutr 2009, 12(11):2074-2083.

45. Garasky S, Morton LW, Greder K: The food environment and food insecurity: perceptions of Rural, Suburban, and Urban Food Pantry Clients in lowa. Family Econ Nutrition Rev 2004, 16(2):41-48.

46. Morton LW, Bitto EA, Oakland MJ, Sand M: Solving the problems of lowa food deserts: food insecurity and civic structure. Rural Sociol 2005, 70 (1):94-112

doi:10.1186/1479-5868-9-41

Cite this article as: Walker et al: Do residents of food deserts express different food buying preferences compared to residents of food oases? A mixed-methods analysis. International Journal of Behavioral Nutrition and Physical Activity 2012 9:41.

\section{Submit your next manuscript to BioMed Central and take full advantage of:}

- Convenient online submission

- Thorough peer review

- No space constraints or color figure charges

- Immediate publication on acceptance

- Inclusion in PubMed, CAS, Scopus and Google Scholar

- Research which is freely available for redistribution

Submit your manuscript at www.biomedcentral.com/submit 